chorea occurs when the function of the corpus striatum is disrupted, the specific abnormality in Sydenham's chorea is unknown. The response to valproic acid suggests that the defect affects the GABA neurotransmitter system. Possibly the difference in effectiveness of valproic acid between Sydenham's chorea and Huntington's chorea reflects the degree of severity of the pathologic process or, alternatively, indicates a difference in the pathogenesis of the two diseases.

${ }^{1}$ Browne TR. Valproic acid. $N$ Engl f Med 1980;302:661-6.

2 Perry TL, Hansen S, Kloster M. Huntington's chorea: deficiency of gamma-aminobutyric acid in brain. N Engl f Med 1973;288:337-42.

${ }^{3}$ Lenman JAR, Ferguson IT, Fleming AM, et al. Sodium valproate in chorea. Br Med f 1976;ii:1107-8.

${ }^{4}$ Suber DA, Riley TL. Valproic acid and normal CT scan in kinesiogenic familial paroxysmal choreoathetosis. Arch Neurol 1980;37:327.

${ }^{5}$ Loscher W, Schmidt D. Increase of human plasma GABA by sodium valproate. Epilepsia 1980;21:611-5.

\section{Vibrio alginolyticus peritonitis associated with ambulatory peritoneal dialysis}

Vibrio alginolyticus is an unusual human pathogen. It is related to $V$ parahaemolyticus and its natural habitat is the sea. Human infections reported to date have been mostly wound and ear infections in swimmers and others with marine contact. We believe that the following is the first reported case of $V$ alginolyticus peritonitis.

\section{Case report}

A 20-year-old man with end-stage renal failure, who had been receiving treatment for six months with continuous ambulatory peritoneal dialysis, presented with signs and symptoms of peritonitis. Several days previously he had been scuba-diving off the South Australian coast and had changed his peritoneal dialysis fluid on the beach without taking adequate precautions against infection.

He presented with severe abdominal pain, appreciable fever, and signs of peritonism. Samples of macroscopically turbid peritoneal fluid were taken immediately from the Tenckhoff catheter for microscopy and culture. Gram staining showed pus cells but no organisms. Treatment was started with continuous peritoneal lavage with flucloxacillin $(50 \mathrm{mg} / \mathrm{l})$ added to the dialysis fluid. His symptoms improved but oxidase-positive, Gram-negative bacilli resistant to flucloxacillin $(420$ colonies $/ \mathrm{ml})$ were cultured from the first sample of dialysis fluid collected. The treatment was changed to gentamicin $4 \mathrm{mg} / \mathrm{l}$ as Pseudomonas was considered to be the likely infecting organism.

Further identification was carried out using routine biochemical tests. The initial reactions suggested that the organism was possibly a member of the Bacillus genus. Since Gram staining showed lacge Gram-negative rods, however, the organism was resubmitted for appareil procédés d'identification (API) and conventional tests. As the API system indicated that the organism was a vibrio (?V cholerae) his history was reviewed and marine vibrio suspected. Further identification procedures showed the organism to be $V$ alginolyticus, sensitive to aminoglycosides, co-trimoxazole, cephalothin, and cephalexin but resistant to ampicillin.

He made a satisfactory recovery over this period, and after four days cultures of the peritoneal fluid were negative and the gentamicin was stopped. He was discharged from hospital taking oral cephalexin and remained in good health.

\section{Comment}

Peritonitis is the most important complication of ambulatory peritoneal dialysis. The infective organism is usually from the patient's own flora and infection occurs after breakdown of the aseptic technique. In this case the infecting organism, $V$ alginolyticus, was of marine origin. It has a worldwide distribution ${ }^{1}$ and can be isolated from fish and crustacea. ${ }^{2}$ It differs from $V$ parahaemolyticus in that it ferments sucrose, is Voges-Proskauer positive, will grow in both $8 \%$ and $10 \%$ sodium chloride, and swarms on blood agar. An unusual cause of human infection, $V$ alginolyticus has usually been associated with skin and ear infections ${ }^{1-5}$ acquired in a marine setting. To our knowledge $V$ alginolyticus peritonitis has not been reported previously.
Patients with indwelling Tenckhoff catheters, and especially those receiving ambulatory peritoneal dialysis, should be advised of the infective risk of swimming in salt water. When such patients with marine contact develop peritonitis the possibility that the causative organism may be a marine vibrio, such as $V$ alginolyticus, should be considered.

${ }^{1}$ Schmidt $\mathrm{U}$, Chmel $\mathrm{H}$, Cobbs $\mathrm{C}$. Vibrio alginolyticus infections in humans. 7 Clin Microbiol 1979;10:666-8.

2 Prociv P. Vibrio alginolyticus in Western Australia. Med $\mathcal{J}$ Aust 1978;2: 296.

${ }^{3}$ Pien F, Lee K, Higa H. Vibrio alginolyticus infections in Hawaii. $\mathcal{f}$ Clin Microbiol 1977;5:670-2.

${ }^{4}$ Rubin SJ, Tilton RC. Isolation of Vibrio alginolyticus from wound infections. $\mathcal{F}$ Clin Microbiol 1975;2:556-68.

${ }^{5}$ Ryan WJ. Marine vibrios associated with superficial septic lesions. $\mathcal{f}$ Clin Pathol 1976;29:1014-5.

(Accepted 29 April 1981)

Departments of Microbiology and Nephrology, The Royal Melbourne

Hospital, Melbourne, Victoria, Australia 3050

ROD TAYLOR, MB, BS, nephrology resident

MALCOLM MCDONALD, FRACP, microbiology registrar

GRAEME RUSS, FRACP, nephrology registrar

MARA CARSON, RT, microbiology technologist

ELIZABETH LUKACZYNSKI, BAPPSC, microbiology technologist

\section{Respiratory and bulbar paralysis with relapsing hyperthyroidism}

Bulbar paresis occurring in patients with hyperthyroidism is a well-recognised phenomenon. ${ }^{12}$ Reports have cited only difficulty in swallowing and aspiration pneumonia as serious complications of the bulbar weakness. We report a case of hyperthyroid bulbar myopathy that required artificial ventilation to support life.

\section{Case report}

A 49-year-old Chinese woman presented with intermittent diplopia and difficulty in swallowing of three weeks' duration. Swallowing fluids often resulted in coughing and spluttering. She noticed that she could no longer whistle. One week after the onset of the symptoms ethinyloestradio $(50 \mu \mathrm{g})$ daily had been prescribed. In 1958 she had undergone pat iial thyroidectomy for hyperthyroidism in Hong Kong. This had been repeated in 1968 because of a recurrence of hyperthyroidism.

Examination showed a fit woman with a resting pulse of 96 beats/min and normal blood pressure. There was no thyromegaly or thyroid bruit. Diplopia with weakness of the right inferior rectus muscle was present intermittently. No exophthalmos or lid lag was noted. Definite bilateral facial weakness, poor palatal movement, and bilateral tongue weakness were evident. Mild shoulder girdle weakness was present. Tendon reflexes and sensory testing were entirely normal. Routine haematology, electrolyte concentrations, and liver function tests, including creatine kinase activity, were normal. Electromyography and nerve conduction studies were normal, and an edrophonium test $(10 \mathrm{mg})$ was negative. Barium swallow showed no peristalsis. Direct laryngoscopy showed no movement of the cords. Thyroid function tests showed: thyroxine concentration $237 \mathrm{nmol} / \mathrm{l}(18.4 \mu \mathrm{g} / 100 \mathrm{ml})$ (normal $70-140 \mathrm{nmol} / 1 ; 5 \cdot 4-10.9 \mu \mathrm{g} / 100 \mathrm{ml}$ ); unbound thyroxine binding globulin $95 \%(85-110 \%$ of normal pool); and triiodothyronine $2.8 \mathrm{nmol} / \mathrm{l}$ $(182 \mathrm{ng} / 100 \mathrm{ml}$ ) (normal $1 \cdot 1-2 \cdot 6 \mathrm{nmol} / 1 ; 72-169 \mathrm{ng} / 100 \mathrm{ml}$ ). A thyroid pertechnetate scan showed increased uptake in the right and pyramidal lobes. The antithyroid (microsomal) antibody titre was $1 / 6400$ and thyroglobulin antibody titre $1 / 320$.

Soon after admission to hospital she required endotracheal intubation and artificial respiration as her vital capacity had fallen below $600 \mathrm{ml}$, she could no longer swallow, and arterial blood-gas analysis showed oxygen pressure $8.1 \mathrm{kPa}(61 \mathrm{~mm} \mathrm{Hg})$, carbon dioxide pressure $7.2 \mathrm{kPa}(54 \mathrm{~mm} \mathrm{Hg})$, and $\mathrm{pH} 7 \cdot 33$. Ventilation was required for six weeks. At the end of this period bulbar and respiratory muscle power had almost recovered. During her admission treatment consisted of carbimazole $20 \mathrm{mg}$ daily and prednisolone $100 \mathrm{mg}$ on alternate days. Thyroid function (biochemically) had returned to normal two weeks before she could be weaned off the ventilator. At follow-up three months later she was well with no symptoms.

\section{Comment}

In patients with hyperthyroidism weakness may be due to a thyrotoxic myopathy, hypokalaemic periodic paralysis ${ }^{3}$ (particularly 
in Orientals), or myasthenia gravis. ${ }^{4}$ Initially, bulbar muscle dysfunction was believed to complicate a pre-existent, proximal skeletal muscle weakness. Kammer and Hamilton ${ }^{2}$ and other workers showed that hyperthyroid patients without evidence of chronic myopathy sometimes presented with dysphagia. Such patients complained of dysphagia, nasal regurgitation of solids and liquids, voice changes, diplopia, facial paresis, and diminished tongue strength. Nasogastric feeding and intensive physiotherapy to protect the airway was sometimes required. This patient presented acutely and had all of these symptoms but, unlike similar patients, required artificial respiration for six weeks because of complete paralysis of laryngeal

This case shows that hyperthyroid patients without chronic myopathy may present with a disabling non-myasthenic bulbar myopathy that may require intubation or tracheostomy because of the acute bulbar paralysis.

1 Joasoo A, Murray IPC, Steinbeck AW. Involvement of bulbar muscles in thyrotoxic myopathy. Aust Ann Med 1970;4:338-40.

${ }^{2}$ Kammer GM, Hamilton CR. Acute bulbar muscle dysfunction and hyperthyroidism. A study of four cases and review of the literature. Am $\mathcal{F}$ Med $1974 ; 56: 464-70$.

${ }^{3} \mathrm{Ali} \mathrm{K}$. Hypokalaemic periodic paralysis complicating thyrotoxicosis. Br Med 尹 1975;iv:503-4.

- Millikan CH, Haines SF. The thyroid gland in relation to neuro-muscular disease. Arch Intern Med 1953;92:5.

(Accepted 1 May 1981)

Department of Neurology, Royal Perth Hospital, Perth, Western Australia 6001, Australia

J EDELMAN, MB, BS, medical registrar

E G STEWART-WYNNE, MRCP, FCP(SA), neurologist and intercostal muscles and inability to swallow.

to show $L$ pneumophila in his sputum, transtracheal aspirate, and transbronchial biopsy specimens. Examination of the cerebrospinal fluid showed no abnormality on two separate occasions. There was a rise in Legionella fluorescent antibody titre from $1 / 16$ at five days to $1 / 512$ at four weeks.

Limitation of upward gaze was the only residual neurological sign after recovery and this improved slowly. Two months after artificial ventilation was discontinued he still had restricted lung function and carbon monoxide transfer was $40 \%$ of that expected.

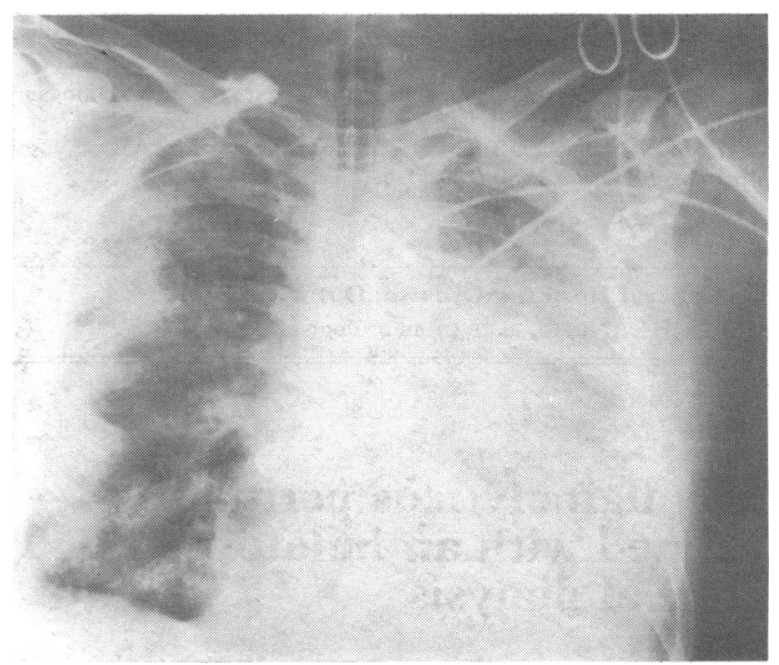

Chest $x$-ray film showing bilateral pulmonary disease leading to the development of adult respiratory distress syndrome in a patient with legionnaires' disease.

\section{Comment}

\section{Pronounced cerebellar features in legionnaires' disease}

Confusion and disorientation are common in legionnaires' disease, and isolated localising neurological signs occur occasionally. We report a case of Legionella pneumophila pneumonia associated with pronounced cerebellar disease.

\section{Case report}

A 47-year-old man presented with a 48-hour history of malaise, generalised weakness, and shivering attacks, associated with production of mucopurulent sputum. In the 24 hours before admission he had had several episodes of vomiting and diarrhoea and his gait had become so unsteady that he was barely able to stand. On waking on the day of admission he had pronounced slurring of his speech.

Since undergoing a splenectomy for hereditary spherocytosis 29 years previously he had had several episodes of pulmonary embolism and deep vein thrombosis and remained permanently on anticoagulants, but his therapeutic compliance was poor. He smoked 40 cigarettes and drank at least eight pints of beer each day, but had continued regular work.

On admission he appeared distressed (respiratory rate $30 / \mathrm{min}$ ) and feverish $\left(38 \cdot 6^{\circ} \mathrm{C}\right)$ with a pulse rate of $100 / \mathrm{min}$. There were crepitations and rhonchi throughout both lung fields. Despite pronounced dysarthria he was orientated in time, place, and person, and he co-operated during history and examination. Examination of cranial nerves showed no abnormality but nystagmus was present. Co-ordination was impaired on finger-nose testing, and he had associated dysmetria and dysdiadochokinesia. Co-ordination on heel-toe testing was similarly impaired, with slight weakness in the left leg. Plantar responses were flexor. There was shadowing in the lingula area on a chest $x$-ray film. Investigations showed a haemoglobin concentration of $16.7 \mathrm{~g} / \mathrm{dl}$, white cell count of $24 \times 10^{9} / 1$ (mainly neutrophils), urea concentration of $9.6 \mathrm{mmol} / 1(57.6 \mathrm{mg} / 100 \mathrm{ml})$, and serum sodium concentration of $127 \mathrm{mmol}(\mathrm{mEq}) / 1$. Despite improving initially with intravenous ampicillin he had a sudden cardiorespiratory arrest on the fifth day of his illness. Legionnaires' disease was considered at this stage, and intravenous erythromycin was given for two weeks followed by amikacin, metronidazole, and cloxacillin because of persistent fever and raised white cell count. Ventilation had to be continued for six weeks, during which time he developed the clinical and radiological signs of adult respiratory distress syndrome (figure). Hepatic and renal function deteriorated during this period but returned to normal with conservative treatment. Dieterle silver stain consistently failed
Many of the clinical features of legionnaires' disease were present in this case. ${ }^{1}$ Although isolated ataxia has been described there has been only one well-documented account of profound cerebellar disease. $^{2}$ In all but one case in which neurological signs have been reported the cerebrospinal fluid was normal. ${ }^{2} 3$ Alcohol was considered as a cause of this man's cerebellar signs, but he regularly took Brewer's yeast tablets $(0.2 \mathrm{mg}$ thiamine daily), there was no evidence of an encephalopathy or delirium tremens, and the onset of acute cerebellar signs began 48 hours after his initial symptoms and were thus directly related to the onset of legionnaires' disease.

There were other interesting features in this case. Firstly, legionnaires' disease occurs more often in compromised hosts or in patients with underlying pulmonary disease, and splenectomy in this man may have further increased his susceptibility. ${ }^{45}$ Secondly, recovery occurred only after six weeks' artificial ventilation, and this is unusual though a permanent diffusion defect remains. Legionnaires' disease should be considered in all cases of pneumonia associated with cerebellar signs. case and the staff of the intensive care unit, Royal Liverpool Hospital, for help in preparation.

1 Swartz MN. Clinical aspects of legionnaires' disease. Ann Intern Med 1979;90:492-5.

2 Shetty KR, Cilyo CL, Starr BD, Harter DH. Legionnaires' disease with profound cerebellar involvement. Arch Neurol 1980;37:379-80.

${ }^{3}$ Friedman HM. Legionnaires' disease in non-legionnaires: a report of five cases. Ann Intern Med 1978;88:294-302.

4 Saravolatz LD, Burch KH, Fisher E, et al. The compromised host and legionnaires' disease. Ann Intern Med 1979;90:533-7.

5 Gump D, Frank R, Winn WC, Foster RS, Broome CV, Cherry WB. Legionnaires' disease in patients with associated serious disease. Ann Intern Med 1979;90:538-42.

(Accepted 1 May 1981)

\section{University of Liverpool, Liverpool $\mathrm{L} 69 \mathrm{3BX}$}

MICHAEL R MASKILL, MB, MRCP, lecturer and honorary senior registrar in clinical pharmacology

Royal Liverpool Hospital, Liverpool

E CLARE JORDAN, MB, FFARCS, anaesthetic registrar
We thank Dr M L'E Orme and Dr P Drury for allowing us to report this 